\title{
Group set-up for printed circuit board assembly
}

\author{
TALI F CARMON , ODED Z. MAIMON: and \\ EZFY M. DAR-EL
}

\begin{abstract}
The current practice in the asscmbly of electronic components on printed circuit boards (PCBs) is serial production, a process characterized by very long set-up times. However, with the advent of efticient on-line process information. new production control methods are now possible. This paper proposes a differen production method, called the group set-up (CSU) method, which can significanty reduce setup litues. The traditional and the GSU production methods are compared and is is shown that the GSU always performs better than the traditional method in terms of lotal production flow (throughput) and labour time. However, the traditional nethod performs better than the GSU in terms of work in process (WIP) inventory and in some cases, in terms of makespan (lead time) A detaled analysis for a small number of PCBs is presented.
\end{abstract}

\section{Introduction}

The serial tradition production method used in the assembly of electronic components on printed circuit boards (PCBs) requires new setups of all components to be assembled on the machines, each time the PCB type is changed. This procedure results in extended set-up times, since even components that are common to the subsequent PCB will need to be set-up again. Its advantage, however, lies in the simplicity of both the production planning and the operational control of the production system.

Traditionally, two main approaches are employed for reducing the overall set-up time needed for production. The first approach simply enlarges the lot sizes and reduces the set-up frequency (Afentakis et al 1984, Maxwell and Muckstadt 1985). However, in many instances, the lot size is prefixed and canmot be increased. Furthermore, entarging the lot size also means enlarging the cost of the work in progress (WIP) inventory.

The second approach is essentially based on group technology (GT) concepts. The main idea underlying GT is that production and layout are product based. This approach uses the "product-based families" concept, which can be defined as a "classification of the products into groups, calling for the use of similar components, for which production sequences can be developed' (Boyle 1986) Thus, jobs (PCBs) should be sequenced such that job followcrs will require the same resources (tools, parts), eliminating much of the set-up between them. This method has been used by many authors (e.g. Tang 1986), with most applications being in the metal-processing industry. Another variation of this concept (Kusiak et al. 1985 ) scheduled products requiring the same limited resources (jigs, fixtures, etc) separately from each other, so as to reduce the waiting periods for these resources. We refer to this as sequence-dependent scheduling. 


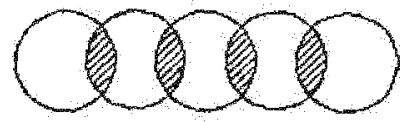

(a)

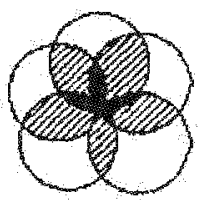

(b)

Figure 1. (a) Sequence-dependent scheduling. (b) The GSU production method.

A schematic presentation of sequence-dependent scheduling is shown in Fig. 1 (a). The marked spaces represent the set-up time savings using this method.

This approach, however, cannot be applied easily to the assembly of electronic components on PCBs. The sequence-dependent scheduling problem is shown to belong to the travelling salesman (TSP) type problem, which is NP-complete (Cunningham and Browne 1986, Lawler et al 1985, Lin and Kemigham 1973, Rinnooy-Kan 1976). Its complexity is even greater for the electronic components assembly problem, since the production requirement is to sequence at least two machines, with the optimal schedule determined by solving a special TSP type problem for the total assembly system. There is no optimum seeking technique for this special TSP structure, and there is no beuristic method known to be able to tackle this problem efficiently, when the set-up times are not negligible.

In this paper, we propose the group set-up (GSU) method as a new approach to significantly reduce the overall set-up times and increase production flow in PCB assembly. The technical background on which this method is based is analysed in the next section.

\subsection{Technical background}

The special characteristic of the PCBs structure is that a large percentage of all the component types used may be regarded as bighly common, often incorporating about $80 \%$ of each product (since most of them appear more than once in each PCB). This characteristic is especially frequent in digital PCBs (as against analogue PCBs, in which there are typically less components which are shared among different $\mathrm{PCBs}$ ).

With larger production it is economically justified to dedicate one or more machines to the assembly of these components (C. H. Mangin, personal communication, 1986). This policy is referred to as a static operating policy" (Lofgren and McGinnis 1986) as against a 'dynamic operating policy', in which the components are switched to whatever is required by the subsequent product.

There are situations, however, in which the production volume may not justify the purchase of dedicated machines for the assembly of common components (a typical machine may cost up to U.S. $\$ 0.7$ million). A single machine should give a production volume of $50000-75000$ PCBs per shift per year (computed for an average amount of 250 components per board, and an average machine rate of $3000-12000$ assembled components per hour (DynaPert-Precina Ltd. 1986, Universal Instruments Inc. 1986). With some production environments, when a stall number of different PCBs is produced, it is possible to dedicate special iocations on the machines for the assembly of 
common components (Cunningham and Browne 1986). However, this cannot apply to situations whereby many different PCBs are to be produced, such as found in subcontractors' plants, where they typically produce to the orders of many different customers. Such applications result in many types of electronic components, which are shared among several PCBs.

The production plans in these environments are highy flexible. There ate many combinations of PCBs that are possible to produce, whose common components vary from one combination to another. Their combined quantity usually exceeds the machine capacity (a typical machine can contain between 100 and 300 different component types), so that it is impossible to allocate a fixed location for each common component on the machine.

\subsection{Basic assumptions}

(1) The production environment that can benefit most from the implementation of the GSU method is a high-mix low-volume production environment. The basic production line consists of two machines a DIP insertion machine and an axial/radial lead components insertion machine.

(2) There is an order constraint on the processing of the PCBs, which forces them to be processed first on machine 1 and afterwards on machine 2 (flowshop type assembly line). The reason is that larger components ICs/DIPs integrated circuits/dual in-line packages) should be assembled before the smaller ones (axial and radial-iead components), because their machine's head is larger and may hit the smaller components if they are inserted first. This constraint is not critical in the placement of SMCs (surface-mounted components-the future technology of clectronic components), so that the production is more flexible (one lot can start bcing produced on machine 1 , while the other can start on machine 2).

(3) The set-up time considered in this paper is only the set-up time required when the product type to be assembled is changed. Refilling components in the machines during the assembly of a lot of identical PCBs is not considered because the amount of components required for the assembly of each $P C B$ does not depend on the production method used, and therefore the refiling operation does not affect the GSU method more than it affects the traditional production method. Also, the machine can continue assembling during the refilling operation, while during set-up for a new product, it must be idle.

(4) The GSU method was originally developed for the major technology currently used for electronics components- the 'thru-hole' technology. Although it is adaptable to the surface-mounted technology, this adoption is not a major concern of this paper:

(5) Due dates are not considered in this paper, except for the determination of the short-term production plan. The method described in this paper is implemented on the short-term production plan after being defined. This is the situation in most practical cases.

(6) This paper is not concerned with the routing of the machine's head on the PCB while assembling the components. The routing problem is a separate problem, dealt with extensively in the literature (Thorogood 1986, Magivou 1986, Gavish and Scidmann 1987). 


\section{The GSU method}

The idea behind GSU is that the products are divided into groups, each of which is produced in two stages. In the first stage, the common components (i.e components that are shared among product types in the group) are set up on the machines, once only for the whole group, and are assembled onto their respective PCBs. We refer to this stage as the common set-up and production. The next stage, referred to as the residual set-up and production, requires the separate set-up and assembly of the remaining components on each product. Therefore, the production stages on each machine are as follows:

(1) set-up of common components;

(2) assembly of common components on all the PCBs in the group;

(3) set-up of residual components; and

(4) assembly of residual components on each PCB separately.

An algorithm for implementing the GSU method is presented in Appendix 1.

A schematic presentation of the GSU method is shown in Fig. 1(b). Again, the spaces marked represent the saving in set-up time. It should be clear that the savings under GSU should exceed that under sequence-dependent scheduling, in which some common components may need to be set-up more than once.

The grouping problem can be viewed as a clustering problem. There are several techniques that can be used in order to define groups (McCormick et al. 1972, Burbidge 1975. King 1980, Kusiak 1984), but it should be noted that the grouping problem should be solved by finding the right balance between the group size and the production time. As the group size is enlarged, the saving in set-up increases, since each product type added to the group typically contains some common components that are already set up on the machine. However, each PCB added also increases the production. makespan and the lead-time of all the PCBs in the group. For this reason, while defining the groups of products, the due dates of all the product types should be considered. A simulation may be used to solve the problem more efficiently. Note, however, that in many practical cases the groups are pre-defined according to the demands of sales/customers.

\section{Comparing the GSU with the traditional production method}

In this section the GSU and the traditional production method are compared using the following three performance measures:

- production flow (throughput)

- labour time

- production makespan (lead time).

Figures $2(a)$ and $2(b)$ show the production flow of two PCB types assembled on two machines using the traditional method and the GSU method, respectively. With the traditional method, each PCB is first completed on machine 1 and then immediately transferred to machine 2 ; whereas with the GSU method, all PCBs are accumulated until all common components are inserted by machine 1. These PCBs are then reprocessed through machine 1 for the insertion of residual components. Processing in machine 2 follows an identical procedure as in machine 1. 


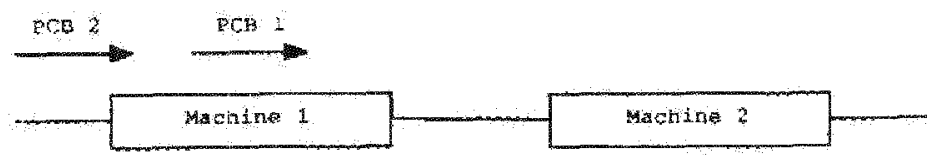

(a)

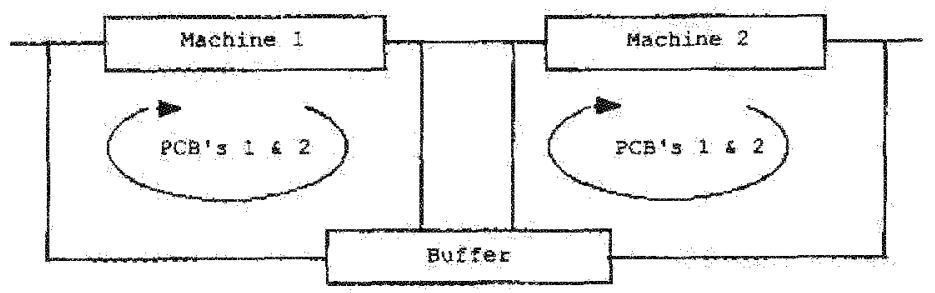

(b)

Figure 2. (a) The traditional production method. (b) The GSU production method.

\section{Assimption}

Orders for PCBs arrive in groups. Within each group there are $n$ different types of PCBs. Each PCB incorporates $J_{k}$ component types $(k=1,2, \ldots, n) . J_{k}$ comprises $J_{k_{1}}$ component types for machire 1 and $J_{k_{2}}$ component types for machine 2 (i.e. $J_{k_{1}}+J_{k_{2}}=J_{k}$ ).

\subsection{Comparing the production flow}

The throughput is inversely proportional to the machines occupation time, so that

$$
p \sim \operatorname{limax}\left\{T_{1}, T_{2}\right\}
$$

where $p$ is the line throughput and $T_{m}$ is machine $m$ occupation time.

In the electronics industry, as in many other industrial environments in which lots are produced in several stages on several machines, there are two practical approaches to production. In the first the stages are totally separated. The lot begins production on the second machine only after the last product is completed on the first machine. The advantage of this method is that machine 2 can operate continuously, with no idle time, since it does aot depend on the production rate of machine 1 . We refer to this approach as 'periodic production'. The second approach, called 'continuous production', applies to products individually iransferred to the next stage immediately following completion in the previous one. As soon as the first product is completed on machine 1 , it is transierred to machine 2 for processing. In this case, machine 2 may have idle times, but the overall production lead-time is reduced.

When the production is periodic, the occupation time of each machine is shorter for the GSU than for the traditional method, since some set-np time is saved for each group on each machine. Therefore, the throughput is higher for the GSU.

When the production is continuous it is always possible (through slippage) to ensure the continuation of production on machine 2 . Therefore the occupation time for both machines is again shorter for the GSU and the throughput is higher.

A more detailed analysis of the production fow and a comparison between the GSU and the traditional production method in terms of throughput and WIP can be found in Carmon (1988) ard in Carmon et al. (1988). 


\subsection{Comparing the labour time}

The total set-up time needed to produce $n$ PCB types using the traditional production method is

$$
S_{\text {tradt }}=s \times \sum_{k=1}^{n} J_{k}
$$

Where $J_{k}$ represents the total number of component types required in PCB type $k$ and $s$ is the set-up time per component. This equation implies that a totally new set-up is needed whenever the $\mathrm{PCB}$ type produced is changed.

The GSU saves set-up time since each component type is set-up once only. In this case, the total set-up time is

$$
S_{\mathrm{gsu}}=s \times\left[\sum_{k=1}^{n} J_{k}-\sum_{i=2}^{n}(i-1) J_{i}\right]
$$

Where $\mathfrak{J}_{i}$ represents the number of component types that are shared among i $\mathrm{PCB}$ types. Clearly, the advantage of the GSU method over the traditional method increases as the amount and the distribution of the common components are increased.

\subsection{Comparing the production makespan for continuous production}

Although the GSU decreases the machine's occupation time, it may increase the PCB's lead time because the method is characterized by an accumulation of the PCBs in the group. In case the lead time is critical, there is a need to formulate the makespan equations for both the GSU and the traditional production methods, in order to investigate the conditions under which each method is advantageous. In this section, we analyse the production networks and develop makespan equations for both methods.

3.3.1. Basic assumptions

In order to maintain simplicity, we constrain our analysis in three ways:

(1) We take each component lype as if it appears only once in the $\mathrm{PCB}$.

(2) Capacity limitations of the machines are ignored, i.e. the conmon set of components is less than or equal to machine capacity. This assumption is realistic because if extra capacity is needed, then extra component heads can be purchased, The method ean also be modified to the performance of more than a single common set-up and production, but this modification is not a major concern of this paper.

(3) There are two PCB types in the group.

\subsubsection{Notation}

$i=1,2 \quad$ PCB-type index variable

$m=1,2$ Machine-type index variable

Ni PCB / batch size

$s$ Set-up time for a single component type on any machine

$R_{m}$ Processing rate of machine $m$ (number of components per hour)

$J_{c}(m)$ Number of components types to be assembled in the common production by machine $m$ (GSU)

$J(i, m)$ Number of components types to be assembled in the residual production of PCB type $i$ by machine $m$ (GSU) 
$J(i, m)$ Number of components types of PCB type $i$ to be assembled by machine $m$ (traditional) $J(i, m)=J_{c}(m)+J_{\mathrm{r}}(i, m)$

$S(i, m)$ Set-up time for PCB type i on machine $m$ (traditional) $S(i, m)=s \times J(i, m)$

$P(i, m)$ Processing time of PCB type $i$ on machine $m$ (traditional) $P(i, m)=J(i, m) / R_{m}$

$T(i, m)$ Batch production time of $\mathrm{PCB}$ type $i$ on machine $m$ (traditional) $T(i, m)=P(i, m) \times N_{i}$

$S_{c}(m)$ Common set-up time for both PCB types on machine $m$ (GSU) $S_{\mathrm{c}}(m)=s \times J_{\mathrm{s}}(m)$

$P_{s}(i, m)$ Common production time of PCB type $i$ on machine $m$ (GSU) $P_{c}(i, m)=J_{c}(m) / R_{m}$

$T_{c}(i, m)$ Batch common production time of PCB type $i$ on machine $m$ (GSU) $T_{c}(i, m)=P_{c}(i, m) \times N_{i}, T_{c}(i, m)=T_{j}(i, m)$ in Fig, $3(b)$

$s_{N}(i, m)$ Residual set-up time for PCB type $i$ on machine $m$ (GSU) $S_{\mathrm{s}}(i, m)=s \times V_{,}(i, m)$

$P_{\mathrm{r}}(i, m)$ Residual production time of $\mathrm{PCB}$ type $i$ on machine $m$ (GSU) $P_{r}(i, m)=J_{r}(i, m) / R_{m}$

$T_{r}(i, m)$ Batch residual production time of $\mathrm{PCB}$ type $i$ on machine $m$ (GSU) $T_{\mathrm{r}}(i, m)=P_{\mathrm{r}}(i, m) \times N_{\mathrm{i}}$

Note that

(1) $2 \times S_{\mathrm{c}}(m)+S_{\mathrm{r}}(1, m)+S_{\mathrm{r}}(2, m)=S(1, m)+S(2, m)$

(2) $P_{s}(i, m)+P_{i}(i, m)=P(i, m)$

\subsubsection{Makespan for the traditional case}

The activity network for the traditional method may be represented as shown in fig. $3(a)$.

Since $T(1,2)$ cannot start until both $T(1,1)$ and $S(1,2)$ are completed, and $T(2,2)$ depends on the completion of $S(2,2)$ and $T(2,1)$, the makespan equation for this network consists of several 'maximum' conditions.

$$
\begin{aligned}
& M S_{\text {irad }}=\max \{[S(1,1)+T(1,1)+S(2,1)+T(2,1)+P(2,2)], \\
& {[\max \{[\max \{[\max \{[S(1,2)],[S(1,1)+P(1,1)]\}} \\
& +T(1,2)],[S(1,1)+T(1,1)+P(1,2)]\}+S(2,2)] \\
& [S(1,1)+T(1,1)+S(2,1)+P(2,1)]\}+T(2,2)]\} \\
& =\max \left\{\left[2 S_{6}(1)+S_{r}(1,1)+S(2,1)+T_{r}(1,1)+T_{d}(2,1)\right.\right. \\
& \left.+T_{r}(1,1)+T_{r}(2,1)+P_{d}(2,2)+P_{r}(2,2)\right] \\
& {\left[\operatorname { m a x } \left\{\left[\operatorname { m a x } \left\{\left[\operatorname { m a x } \left\{\left[S_{d}(1,2)+S_{r}(1,2)\right],\left[S_{c}(1)+S_{r}(1,1)\right.\right.\right.\right.\right.\right.\right.} \\
& \left.\left.+P_{0}(1,1)+P_{\mathrm{T}}(1,1)\right]\right\} \\
& \left.+T_{\mathrm{s}}(1,2)+T_{\mathrm{r}}(1,2)\right],\left[S_{\mathrm{s}}(1)+S_{\mathrm{r}}(1,1)+T_{\mathrm{s}}(1,1)+T_{\mathrm{r}}(1,1)\right. \\
& \left.\left.\left.+P_{q}(1,2)+P_{r}(1,2)\right]\right\}+S_{v}(2)+S_{r}(2,2)\right],\left[2 S_{r}(1)+S_{r}(1,1)\right. \\
& \left.\left.\left.\left.+S_{r}(2,1)+T_{r}(1,1)+T_{r}(1,1)+P_{0}(2,1)+P_{r}(2,1)\right]\right\}+T_{c}(2,2)+T_{r}(2,2)\right]\right\}
\end{aligned}
$$




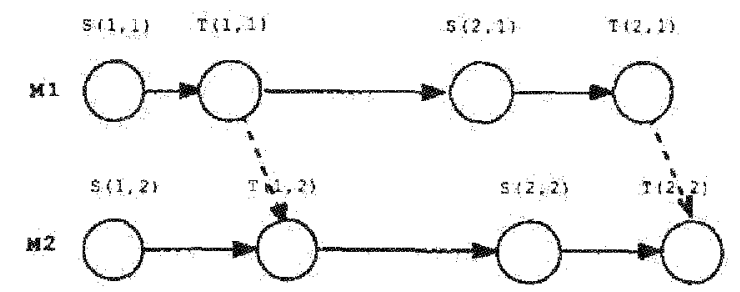

(a)

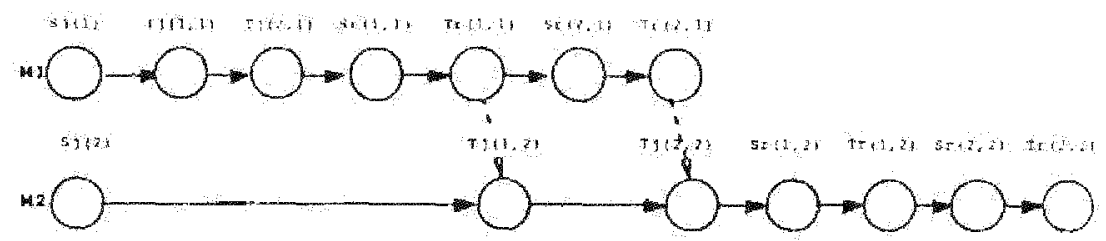

(b)

Figure 3. (a) The activity network for the traditional method. (b) The activity network for the GSU method.

\subsubsection{Makespan for the GSU case.}

The activity network for the GSU method is presented in fig. $3(b)$.

The makespan for this network is

$$
\begin{aligned}
& M S_{\text {pai }}=\max \left\{\left[S_{c}(1)+T_{d}(1,1)+T_{v}(2,1)+S_{v}(1,1)+T_{v}(1,1\}\right.\right. \\
& \left.+S_{r}(2,1)+T_{r}(2,1)+P_{0}(2,2)\right] \text {. } \\
& {\left[\operatorname { m a x } \left\{\left[\operatorname { m a x } \left\{\left[\operatorname { m a x } \left\{\left[S_{d}(2)\right],\left[S_{v}(1)+T_{v}(1,1)+T_{c}(2,1)\right.\right.\right.\right.\right.\right.\right.} \\
& \left.\left.\left.+S_{r}(1,1)+P_{r}(1,1)\right]\right\}+T_{s}(1,2)\right] \text {. } \\
& \left.\left.\left[S_{\mathrm{c}}(1)+T_{\mathrm{s}}(1,1)+T_{\mathrm{s}}(2,1)+S_{\mathrm{s}}(1,1)+T_{\mathrm{T}}(1,1)+\mathrm{P}_{\mathrm{v}}(1,2)\right]\right\}\right] \\
& \left.\left[S_{\mathrm{v}}(1)+T_{\mathrm{s}}(1,1)+T_{\mathrm{c}}(2,1)+S_{\mathrm{r}}(1,1)+T_{1}(1,1)+S_{\mathrm{s}}(2,1)+P_{\mathrm{r}}(2,1)\right]\right\} \\
& \left.\left.+T_{s}(2,2)\right]\right\}+S_{\mathrm{r}}(1,2)+T_{\mathrm{r}}(1,2)+S_{\mathrm{r}}(2,2)+T_{\mathrm{r}}(2,2)
\end{aligned}
$$

\subsubsection{Effects of the various production factors on the production makespan.}

The analysis of the networks shows that when machine 1 is dominant (the process bottleneck-because of lower rate or greater amount of components to assemble), the condition for shorter makespan for the GSU is that the time to assemble the residuals. on the second machine is smaller than the time to set up the common components on the first machine. This is true since the makespan in this case is equal to the machine occupation time plus the time required for the residual production on machine 2 . Such a situation is unlikely to happen, but could happen if the amount of the residual components to be assembled on machine 2 for both PCBs is very small and/or the amount of common components on machine 1 is very large.

When machine 2 is the bottleneck, the probability that the GSU performs better than the traditional method is increased, depending on the waiting periods on machine 2 for the PCBs produced on machine 1 (this is true, of course, only when the production on machine 2 is not delayed so that waiting times are eliminated). These waiting periods are lengthened if the common production on machine 1 is longer than the common set- 
up of machine 2 , and if the residuals' production on machine 1 is longer than the common production on machine 2 .

When the amounts of the common components required on both machines are large, the GSU typically results in a teduced makespan.

The GSU perform better than the traditional method for all cases where no restriction exists on the order of the production (e.g. it is possible to start assembling components of machine 2 before machine 1 is completed).

The makespan of both production methods under various production conditions is illustrated in Appendix 2.

\section{A simple example}

In an attempt to study the properties of the GSU method, and to compare its performance with that of the traditional method, wo use a simple numerical example of two PCB types produced on two different machines. Examples of such machines are Universal Instruments Inc. (1986) and DynaPert-Precima Ltd. (1986) thru-hole assembly machines. We assume that there is only one machine available of each type, ie, one machine 1 and one machine 2.

\section{Techincal data and constraints}

(1) From data collected in several electronic nanufacturers plants, we take the loading time of one componcnt type on each machine to be 1 minute of operator's work. This time is the set-up time.

(2) We assume that the setup time needed to reload the machines when they run out of components is negligible. This assumption is correct when using most of the insertion tnachines (i.e machines which assemble thru-hole components--the current practice in industry), because their construction enables the operator to reload components while the machines are working. Note, however, that with surfacemounted component (SMC) placement machines, the batch size and the amount of each type of component to be placed on the boards are of importance, since it takes some set-up time to reload the machines.

(3) The machines rates (including loading the PCBs) are

Machine 1; 4000 eomponents per hour;

Machine 2: 10000 components per hour.

(4) The difference between transfer times of components which are closer to the machine's head and components which are further from it is negligible $(0.1-0.3 \mathrm{~s})$. For this reason, there is no point in spliting set-up and production in order to shorten the transfer times of farther-located components.

The PCBs specifications are as follows:

\begin{tabular}{ccccc}
$\begin{array}{r}\text { PCB } \\
\text { type }\end{array}$ & $\begin{array}{c}\text { Machine } \\
\text { type }\end{array}$ & $\begin{array}{c}\text { Total number of } \\
\text { components }\end{array}$ & $\begin{array}{c}\text { Number of commont } \\
\text { components }\end{array}$ & $\begin{array}{c}\text { Batch } \\
\text { size }\end{array}$ \\
\hline 1 & 1 & 100 & 60 & 100 \\
& 2 & 100 & 90 & \\
2 & 1 & 100 & 60 & 100 \\
\hline
\end{tabular}

Table. 


\section{The labour time}

Using the serial traditional production method, the time taken for set-ups is

For PCB type $1:(100+100) \times 1=200$

For $\mathrm{PCB}$ type $2:(100+100) \times 1=200$

The total set-up time in the process is $400 \mathrm{~min}=6.66$ hours.

The net processing time of the batches is

$$
[(100+100) / 4000+(100+100) / 10000] \times 100=7 \text { hours }
$$

i.e.

$$
\frac{\text { set-up }}{\text { production }}
$$

is about $49 \%$, meaning that the setup time is about $\frac{1}{2}$ of the total production time.

Using the GSU method, the set-up time for the production is

$$
\begin{aligned}
\text { Common set-up time: } & (60+90) \times 1=150 \\
\text { Residual set-up times: } & \\
\text { For PCB type 1: } & (40+10) \times 1=50 \\
\text { For PCB type 2: } & (40+10) \times 1=50 \\
\text { Total set-up timc: } & 250 \mathrm{~min}=4.17 \text { hours }
\end{aligned}
$$

Using the GSU method, the labour time consumed by set-up in the process is reduced by $37.5 \%$ and the ratio

$$
\frac{\text { set-up }}{\text { production }}
$$

is about $37 \%$ i.e the set-up time is now about $\frac{1}{3}$ of the production time.

\subsection{The production flow}

The production flow is inversely proportional to the machines occupation time. Using the traditional production method, the machines' occupation times are

For PCB type 1 on machine 14.17 hours

For PCB type 2 on machine 14.17 hours

For PCB type 1 on machine 2. 2.67 hours

For PCB type 2 on machine $2 \quad 267$ hours

Machine 1 total occupation time is 8.34 hours.

Machine 2 total occupation time is 5.34 hours:

Using the GSU production method, the machines' occupation times are

For PCB types 1 and 2 on machine $1 \quad 7.33$ hours

For PCB types 1 and 2 on machine 23.83 hours.

\subsection{The production makespan}

Computation of the makespan yields the following results:

The makespan using the traditional method is $M S_{\text {trad }}=8.35$ hours.

The makespan using the GSU method is $M S_{\mathrm{gsu}}=7.89$ hours. 
For the particular case, the GSU performs better than the traditional production method in terms of the production makespan.

\section{Complexity}

The complexity of implementing the GSU method involves four factors:

(1) the complexity of the 'grouping' method;

(2) the complexity of the production management and the information control;

(3) the complexity of the practical production environment; and in the case of continuous production,

(4) the complexity of the makespan calculation.

(1) Clearly, the grouping problem is very complicated. However, in many practical cases, the group, which is actually the short-term production plan, is pre-defined by the sales/customers demands (the PCB's due-dates).

(2) While reducing the overall set-up times, this new approach also complicates production management and information control. The information system must now be able to control simultaneously all data related to the production and in-process inventory of different PCB types. However, the current accelerated development of information systems should be able to control large amounts of production and process data, enabling the implementation of this more complicated but more efficient production method.

(3) The complexity of the production envitonment depends on many factors which affect the assembly process and the scheduling methods used. Among them are PCB variety, component variety, fluctuations in demand, machine downtime and lot size. The impact of these factors is not discussed here, but they should be considered when a scheduling method for the assembly of PCBs is selected.

(4) It can be shown that the makespan calculation can be done in $O(\mathrm{~nm})$ time, where $n$ is the number of PCB types in the group and $m$ is the number of machines. The number of 'max' expressions in the equation is $2 n(m-1)$, and the number of figures summed is also a function of $n$ and $m$. This results in a calculation that grows polinomialy with the problem size and a reasonable computer time consumed.

\section{Conclusions and further research}

The GSU was shown to perform better than the traditional (serial) production method in terms of

- labour time

- total production llow (throughput)

and in some cases also in terms of

- the production makespan (lead time).

The GSU complicates the WIP inventory control, but such advanced information and production control system are currently available.

The advantage of the CSU method is especially important for production cnvironments in which there are many types of products sharing "common" components, and where the production volume justifies the purchase of only one machine of each type.

The GSU approach needs to be further developed for more PCB types and more machines. An efficient grouping method needs to be defined. The effect of lot size on the 
production makespan also needs to be further analysed. There are other possibilities of sequence-dependent scheduling for the cases of less common components or less PCB types, and a comparison belween these other possibilities and the GSU needs to be developed. One such method and a comparison between this method and the GSU method is described in Carmon (1988) and Carmon et al. (1988).

\section{Appendix 1: The major set-up algoritlum}

(The algorithm is implemented for each machine separately.)

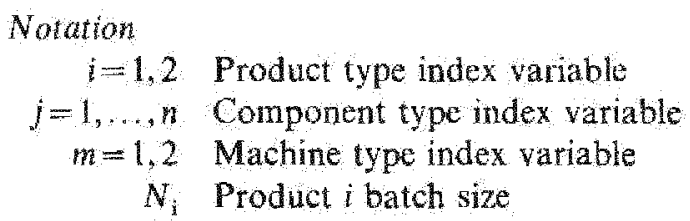

$A_{i j}$ Amount of component $j$ needed to produce one unit of product $i$

$E_{i j}=0,1$ Binary variable which is 1 if product type $i$ contains a $j$ component and is 0 otherwise

$V_{1}$ Amount of various product types each component is shared among

$$
V_{j}=\sum_{i} E_{i j}
$$

$W_{j}$ Total amount of component $j$ needed for the production of all the products in the production plan

$$
W_{j}=\sum_{i} A_{i j} N_{i}
$$

$C_{\mathrm{m}}$ Machine capacity (components feeders)

\section{Preliminary step}

Define the groups of boards to be produced according to their size. All the boards in the group should have at least one equal dimension. This dimension will define the conveyer's width, so that no mechanical set-up (i.e. changing the width of the conveyers which carry the boards) will have to be made between the assembly of two different boards within the same group, since the mechanical set-up is time-consuming (a typical mechanical set-up for one machine can take up to $30 \mathrm{~min}$ ) and must be avoided (Mangin 1985).

The PCBs dimensions can be controlled by using 'panelling', a production method in which the boards are assembled as 'panels', each panel containing several boards, and cut at the end of the production process into their desired dimensions.

(1) Compute

$$
V_{j}=\sum_{i} E_{i j}
$$

for each component $j$ in the next group of PCBs to be produced.

(2) Define $j^{*}$, the component with the maximal $V_{j}$. 
(3) If $j^{*}$ is not a singleton then choose the component with the minimal $W_{j}$ where

$$
W_{j}=\sum_{i} A_{i j} N_{i}
$$

For equal $W_{j}$, choose arbitrarily.

(4) Delete $j^{*}$ from the list of components to be assigned.

(5) Repeat steps $2-5$ until the amount of components assigned equals the machine capacity, $C_{m}$ or until $V_{j}<2$

(6) Sort the components chosen according to their $W_{j}$ yalue, and assign them to the machine's feeders so that components with larger $W_{j}$ will be assigned closer to the machine's head (athough the time difference is almost negligible).

(7) If the next $V_{j}$ on the list satisfies $V_{j} \geqslant 2$ then at least one more major set-up should be performed.

Appendix 2: Makespan asing GSU versus traditional method
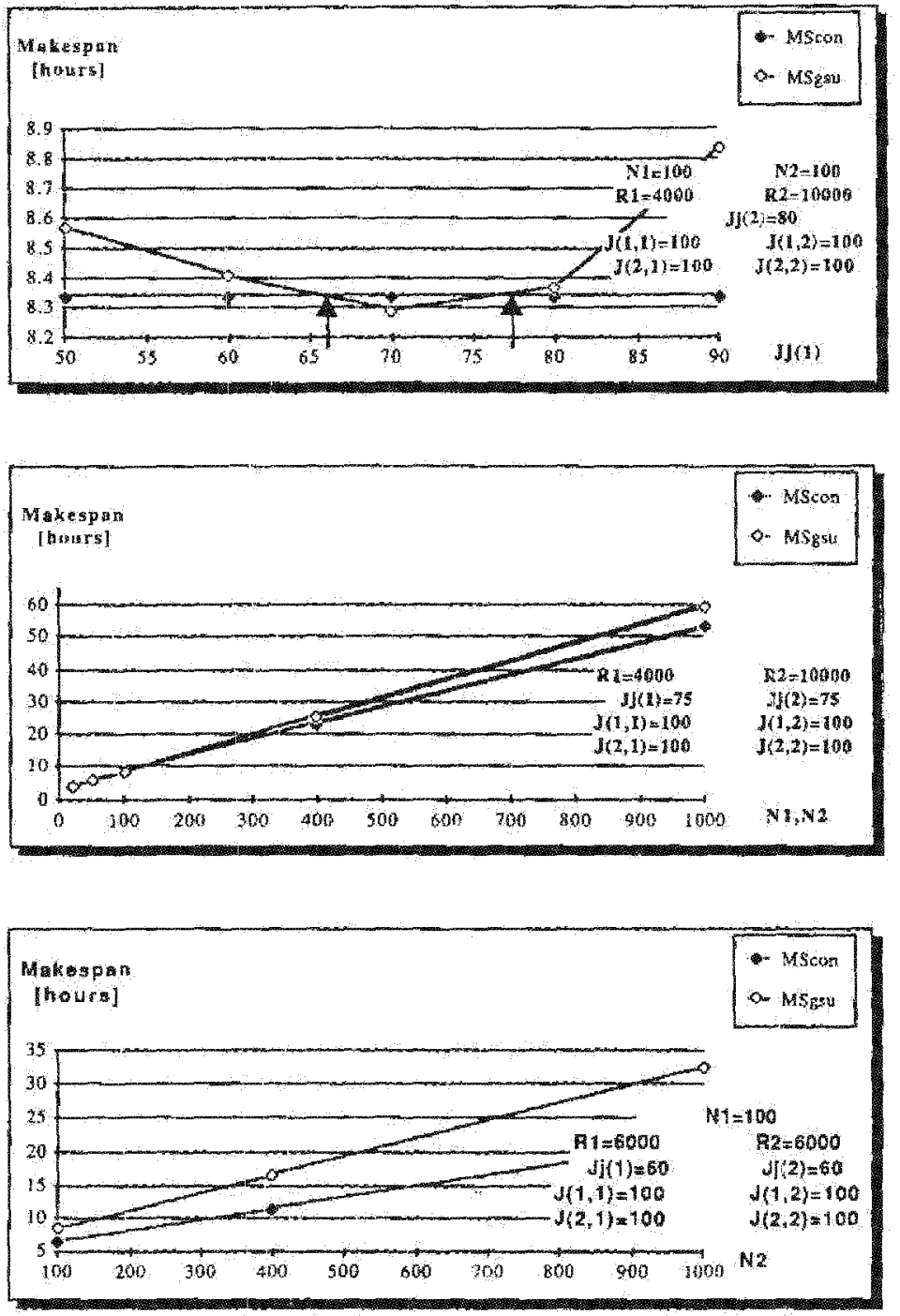

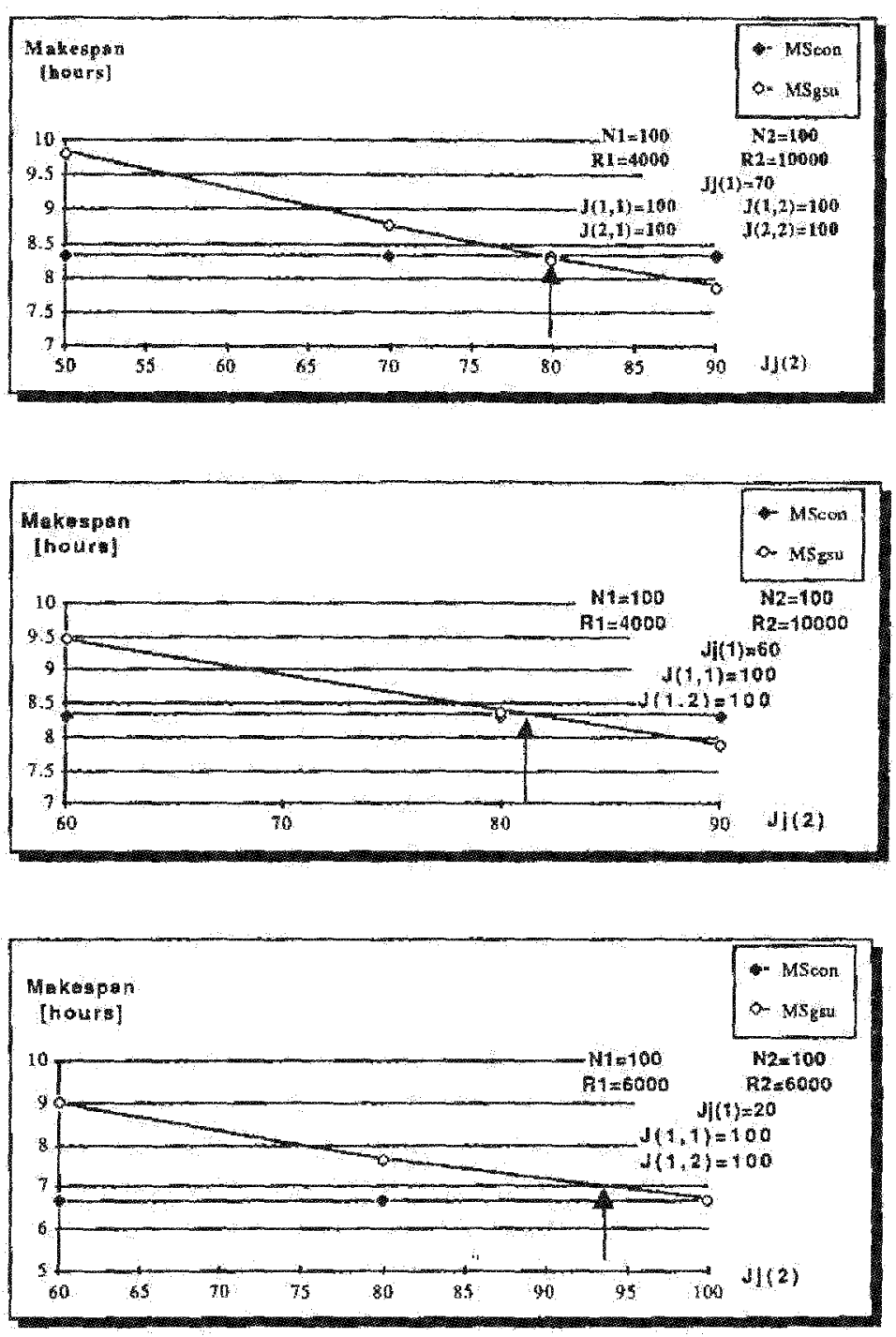

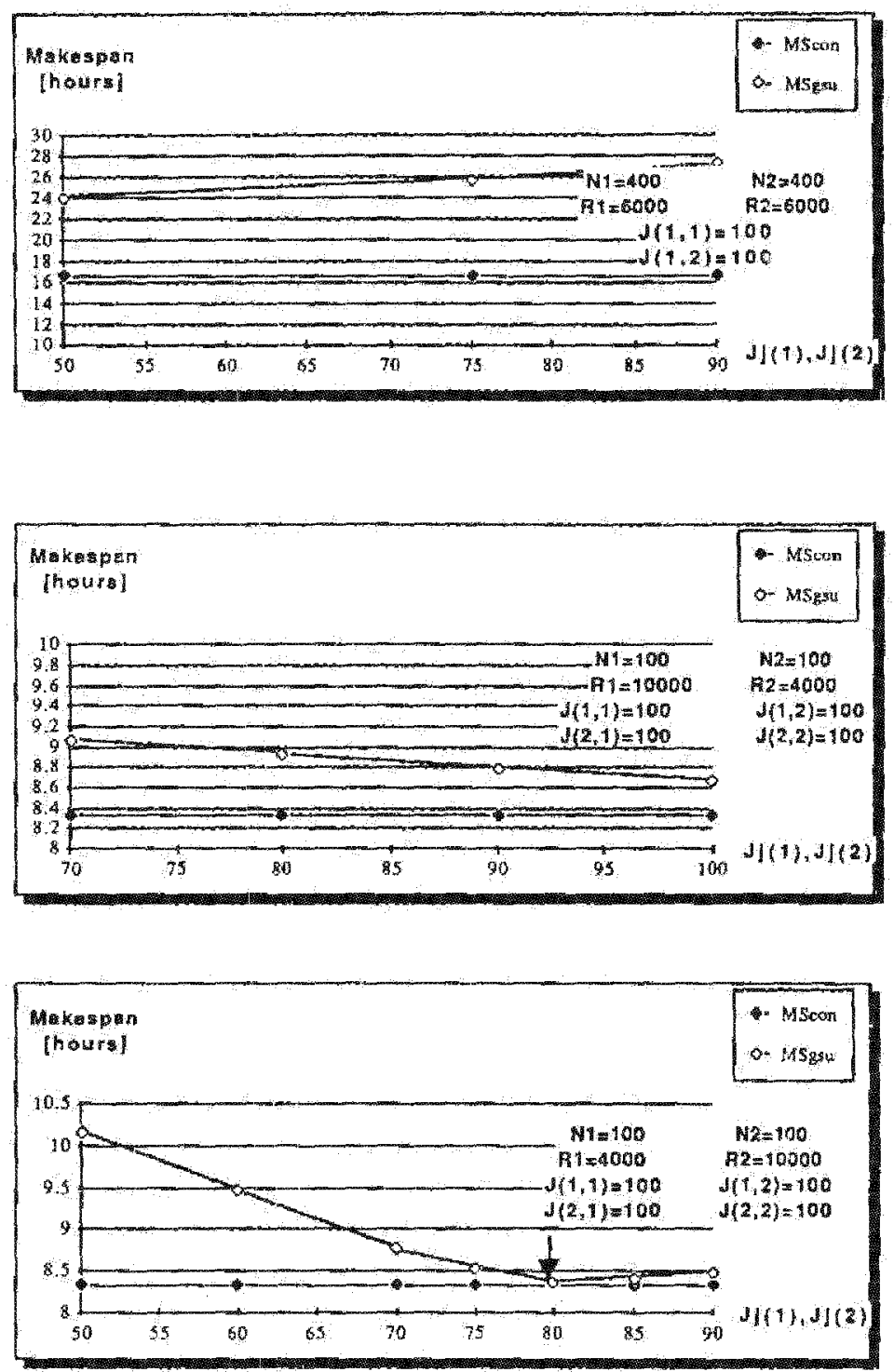


\section{References}

AFENTAKIS, P., GAYISH, R., and KARMRRKER, U. S., 1984, Computationally efficient optimal solutions to the lot-sizing problem in mult-stage assembly systems. Manajement Sience, 30,222 .

BoYLE, $\mathrm{C}, 1986$, The benefits of group technology software for manufact tring Procedings of the IMTS Conference, Chickgo, Illinois, p. 1042

BunbidGE, J L., 1975, The Introduction of Group Technology (New York: Wiley).

CARMON (FREED), T, 1988, Scheduling the assembly of printed circuit boards. M.Sc. Thesis, Technion, Israel.

CARMON (FRED), T, Mamon, O Z, and DAR-E, E M., 1988, Proposed scheduling methods for printed circuit board assembly. CIRP Annals (to be published).

CUNAINGHAM, P, and BRowne, J. 1986, A LISP based heuristic scheduler for antomated insertion in electronics assembly. Intenational Joumal of Production Researd, $24,1395$.

DYNA PERT-PRECMA LTD, 1986, HPDI-I, product brochute and AccuSert, product brochure (Concord, MA: Dynapert-Precina Ltd).

GRYsH, B, and SEDMANN, A., 987 , Printed circuit board assembly automation formulations and algonthms Procedings of the Ninth ICPR Conference, Cincinnati, Ohio, $\mathrm{p} 662$

KNv, J. R., 1980, Machine component gronping in production fow analysis an approach using a rank order clustering algorithm. Imternational Journal of Production Resedrch, 18 , $213-232$.

KUSIAK, A, 1984. Analysis of integer programming formulations of clustering problems. Image and Vision Computing, $2,35$.

KUSIAK, A., VANELLI A, and KUMAR, K. R., 1985, Grouping problem in scheduling flexible manufacturing systems. Robotica, $2,245$.

LAWLER, E L, LENSTRA, J, K. RINNOOY-KAR, A. H. G. and SHMOYS, D. B., 1985, The Travelling Solesman Problem (New York. Wiley).

LN, S, and KerNGHAM, X, 1973, An effective heuristic algorihm for the travelling salesman problem Operations Resecrit, $21,498$.

LoFGren, C. B, and MCGINNs, L. F, 1986, Soft configuration in tutomated insertion. Proceedings of 1986 IEEE International Conference on Robotics and Automation, Vol. 1 (IEEE Computers Society Press), p 138.

Magivou, V. F, 1986, The efficient drilling of printed circuit boards. Interfaces, $16,13$.

MangN, C H., 1985, Scotland atracts the electronics manufacturers. Assembly Automation. February p. 40 .

MAXweLL, W., and MuCKSTADT, J, 1985, Establishing consistent and realistic reorder intervals in production-distribution systems, Operations Research, 33, 1316.

McCormick, W. T. SchwetrzER, P. J, and White, T. W., 1972, Problem decomposition and data reorganization by a clustering technique Operations Research, 20, 993-1009.

Rinnooy-Kan, A E. G, 1976, Machine Scheduling Problems (The Hague: Martious Nijhof).

TANG, C. S. 1986, A job-scheduling model for a flexible manufacturing machine. Procedings of 1986 IEEE International Conference on Robotics and Automation, Vol IIIEEE Computers Society Press, p. 152

THorogood, $\mathrm{T}, 1986$, Optimizing automatic insertion. Electronic Manufacuring and Testing, 5 , 58.

UnIviras Instruments INC, 1986, Automation in Electronics, Product Catalogue (Binghamton, NV: Universal Instruments Inc). 